\title{
A Review of Multicriteria Assessment Techniques Applied to Sustainable Infrastructure Design
}

\author{
Ignacio J. Navarro, ${ }^{1}$ Víctor Yepes $\mathbb{D}^{2}{ }^{2}$ and José V. Martí ${ }^{2}$ \\ ${ }^{1}$ Dept. of Construction Engineering, Universitat Politècnica de València, 46022 Valencia, Spain \\ ${ }^{2}$ Institute of Concrete Science and Technology (ICITECH), Universitat Politècnica de València, 46022 Valencia, Spain \\ Correspondence should be addressed to Víctor Yepes; vyepesp@cst.upv.es
}

Received 10 April 2019; Revised 20 May 2019; Accepted 29 May 2019; Published 17 June 2019

Guest Editor: Endong Wang

Copyright (c) 2019 Ignacio J. Navarro et al. This is an open access article distributed under the Creative Commons Attribution License, which permits unrestricted use, distribution, and reproduction in any medium, provided the original work is properly cited.

\begin{abstract}
Given the great impacts associated with the construction and maintenance of infrastructures in both the environmental, the economic and the social dimensions, a sustainable approach to their design appears essential to ease the fulfilment of the Sustainable Development Goals set by the United Nations. Multicriteria decision-making methods are usually applied to address the complex and often conflicting criteria that characterise sustainability. The present study aims to review the current state of the art regarding the application of such techniques in the sustainability assessment of infrastructures, analysing as well the sustainability impacts and criteria included in the assessments. The Analytic Hierarchy Process is the most frequently used weighting technique. Simple Additive Weighting has turned out to be the most applied decision-making method to assess the weighted criteria. Although a life cycle assessment approach is recurrently used to evaluate sustainability, standardised concepts, such as cost discounting, or presentation of the assumed functional unit or system boundaries, as required by ISO 14040, are still only marginally used. Additionally, a need for further research in the inclusion of fuzziness in the handling of linguistic variables is identified.
\end{abstract}

\section{Introduction}

Sustainable development was first defined in 1987 by the Brundtland Commission as a way to meet the present needs of the society without compromising the ability of future generations to meet their own needs. Sustainable actions and decisions shall therefore be based on the simultaneous consideration of their economic, environmental, and social consequences over time. Sustainable design of products, as an application of the sustainability concept in the industry, takes particular relevance when considering the construction sector. In recent times, construction industry has become one of the main environmental stressors of our society, since it is responsible for $30 \%$ of global energy consumption, $40 \%$ of raw material extraction, and $30 \%$ of greenhouse gas emissions [1]. In particular, only the production of cement for concrete contributes around $8 \%$ of global annual $\mathrm{CO}_{2}$ emissions [2]. On the other hand, investments in public capital, such as infrastructures, promote the economic wellbeing and social development of countries, since they contribute to the territorial structuring of regions and to the adequate provision of services. For example, about 20 per cent of World Bank loans in recent years have been allocated to transport infrastructure [3].

So, given the relevant implications of infrastructure design, and considering that most infrastructures are designed to serve a significant group of people over a long, intergenerational period of time, the assessment of the different dimensions of sustainability related to the infrastructure design has been in the spotlight of many researchers in recent times. Studies have been conducted on cost optimisation of infrastructure design $[4,5]$ and maintenance $[6,7]$. Attention has also been paid to the environmental impacts derived along the life cycle of structures, from bridges [8-10] to buildings [11], as well as those derived from particular construction processes, such as concrete production [12]. Social impacts related to the use of different building materials [13] for building construction [14] and for road infrastructure projects [15] have also been assessed in recent years. However, the current state of science lacks an objective and universal methodology to properly 
assess the sustainability of a particular infrastructure design. Thus, although standardised tools exist to assess the different life cycle impacts of products, there is no consensus on how to cope with the simultaneous consideration of the three pillars that define sustainability, nor on what particular criteria should be considered in the decision-making process of sustainable infrastructure design [16].

To deal with the assessment of the conflicting dimensions of sustainability in a multistakeholder and longterm context like infrastructure design, the use of multicriteria decision-making (MCDM) techniques has revealed itself as the most suitable approach compared to other methods commonly used in infrastructure design, such as single- or multiobjective optimisation. MCDM techniques allow the decision maker to assess complex problems involving multiple and divergent criteria on the basis of the subjective judgements of a panel of experts or of stakeholders affected by the decision. Therefore, this paper is devoted to analysing the current trends regarding the application of MCDM techniques to the sustainability assessment of infrastructure design, paying special attention to the particular criteria considered in these assessments.

The rest of the paper is structured as follows. Section 2 presents the research methodology, exposing the research questions to be answered by means of this manuscript, as well as describing the data acquisition strategy followed in the review. Section 3 presents the results obtained. In particular, Section 3.1 provides a general overview of the gathered data; Section 3.2 presents the indicators selected to characterise each of the three dimensions of sustainability, as well as the methods considered to assess such impacts. Section 3.3 presents a brief review on how qualitative data are treated in the analysed manuscripts; Section 3.4 investigates the normalisation techniques found in the reviewed literature; Section 3.5 describes the weighting techniques used; Section 3.6 presents the methods used in the analysed studies to aggregate the weighted indicators; Section 3.7 offers an overview of the aspects object of sensitivity analyses in sustainability MCDM assessments; Section 3.8 presents how the subjectivity of the experts' judgements is handled throughout the whole decision-making process. Finally, Section 4 provides the conclusions of the present literature review.

\section{Materials and Methods}

2.1. Research Question. The present study formulates two research questions, namely, how MCDM methods have been applied for the sustainability assessment of infrastructures in recent times, and what particular impact criteria and indicators have been considered in these evaluations as representative for the sustainability of an infrastructure design.

2.2. Data Sampling Strategy. The data collection process performed in the present literature review consists of two stages, as shown in Figure 1. The objective of the first stage is to create a preliminary set of contributions to serve as a basis for the construction of a final set through an appropriate filtering and expanding process in a second stage.

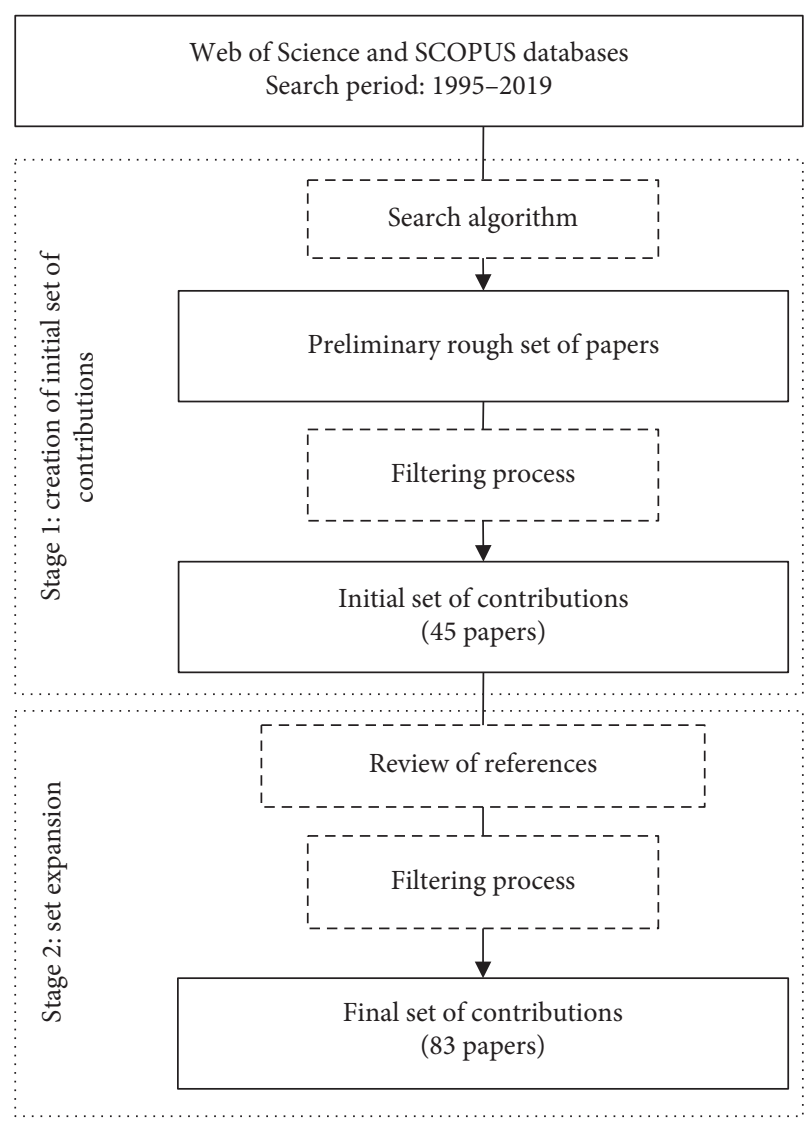

FIgURE 1: Systematic literature review.

The search is carried out through the scientific bibliographic databases SCOPUS and Web of Science. The search period is established from 1995 to 2019, since there is no evidence of relevant contributions before that date. The search algorithm used to identify the articles conforming the preliminary set consists of a combination of the terms "Multi-criteria decision making," "MCDM," and "Sustainability" along with other civil engineering-related terms, such as "Construction" or "Infrastructure," by means of the Boolean operators "AND" and "OR."

To filter the obtained results, some exclusion criteria have been followed to build the first set of papers. First, only original, peer-reviewed scientific articles and conference proceedings are included. Secondly, those manuscripts that do not clearly identify either the MCDM technique used or the sustainability criteria considered are excluded. Third, articles are required to consider at least two of the three dimensions of sustainability in the assessment through an appropriate selection of decision criteria. Finally, it should be taken into account that only articles written in English are considered in this study. This structured filtering process resulted in an initial set of 45 papers.

Once the initial set of contributions is generated, the references included in the selected manuscripts are then reviewed and analysed. The set is then expanded by applying the filtering process exposed above to the articles referenced in the papers included in the first set, which results in a final and expanded set of manuscripts. This sampling technique 
has been used previously in other literature review works $[17,18]$. The expanded final set has resulted here in 83 contributions.

\section{Results and Discussion}

3.1. General Overview of the Retrieved Data. Although in 2007 there was a first rebound in the number of publications regarding sustainability assessment of infrastructures, the number of contributions increases drastically in 2015 (Figure 2). Over $50 \%$ of the publications applying MCDM techniques to sustainable infrastructure design were made between 2015 and the present. This increase is explained by the fact that it was in 2015 when the General Assembly of the United Nations established the Sustainable Development Goals for the first time. Among the 17 Goals set, some of them are related to sustainable economic growth, decent work, resilient and sustainable infrastructures, and climate action. This would explain the great efforts made by the scientific community since 2015 to contribute to providing tools that allow the sustainable design of infrastructures. After reviewing the gathered data, 6 different main applications of MCDM techniques were identified:

(i) Buildings. $38.6 \%$ of the analysed contributions (32 papers) are devoted to assess the sustainability of different aspects related to the design of buildings. While some authors have focused on the design assessment of particular elements of the building structure, such as slabs $[19,20]$, columns [21], and beams [22], others pay attention to the sustainable design of building envelopes [23-31]. Pons and Aguado [32], Akadiri et al. [33], Motuziene et al. [34], Samani et al. [35], and Nassar et al. [36] also compare the sustainability of the application of different construction materials to buildings. Research is also conducted on the development of indicators suitable to measure the sustainability of buildings [37-41]. Particular attention is paid to the sustainable design of industrial buildings [42-45]. Formisano and Mazzolani [46], and Terracciano et al. [47] evaluate the sustainability of different alternatives for energetic retrofitting of buildings in locations with high seismicity. Finally, other purposes are covered, such as restoration alternatives for derelict buildings [48, 49], or optimal building location [50].

(ii) Bridges. $15.7 \%$ of the reviewed manuscripts (13 papers) deal with the sustainability assessment of bridges. Most of them focus either on the sustainability of bridge deck designs [51-57] or on the selection of optimal maintenance strategies [58-60]. Attention is also paid to the sustainability of different strengthening or repair schemes $[61,62]$ and to the selection of the most sustainable construction method [63].

(iii) Energy Infrastructure. $14.5 \%$ of the papers (12 articles in total) deal with the sustainability of different topics related to energy infrastructure, such as the selection of the most sustainable energy production system [64-70], the selection of the optimal location of energy production plants [71, 72], and the sustainability performance evaluation of different designs of wind turbines and towers [73-75].

(iv) Hydraulic Infrastructure. $13.3 \%$ of the publications handle with the sustainability of different hydraulic infrastructures, such as dams [76-78], urban drainage [79-81], sewerage systems [82], and water supply systems [83-86].

(v) Transport Infrastructure. $7.2 \%$ of the manuscripts deal with the sustainability of different elements and topics related to transport systems, such as the sustainable design of road pavements [87-90], the selection of the optimal road location [91], or the development of assessment tools for the evaluation of transport projects [92].

(vi) Others. The remaining papers reviewed (10.7\%) cover a variety of aspects related to sustainable infrastructure design, such as the assessment of tunnel projects [93, 94], ports [95], location of demolition waste facilities [96], the selection of coating materials for construction [97], and the development of assessment tools for the evaluation of construction projects in general terms [98-101].

3.2. Impact Assessment and Selection of Indicators. As sustainability life cycle assessments are based on the life cycle impacts derived from the different activities considered in the analysis, it is essential to define in the early stages of the decision process not only which impacts (criteria) are going to be considered in the analysis, but also how those impacts are going to be assessed. Of the analysed publications, 74.7\% (62 papers) base their assessments on the impacts derived from at least two different stages of the life cycle of the infrastructure under study. To evaluate the life cycle impacts and establish coherent impact categories, an objective methodology has been standardised in the environmental field $[102,103]$ to allow a rigorous assessment of different alternatives. Although such an ISO standard does not yet exist for the economic field, life cycle costing shows a highly mature state of development [104]. However, the evaluation of the social dimension of sustainability is still under development. It was first in 2009 when an attempt was made to establish an objective methodology to identify and evaluate social impacts through the "Guidelines for social life cycle assessment of products" [105], which relies on the ISO standardised methodology for environmental impact assessments. Notwithstanding the above, only 4 out of the 83 reviewed papers (4.8\%) follow the ISO methodology, explicitly defining an adequate functional unit and the system boundaries assumed in the assessment $[20,34,35,70]$. Although not strictly following the ISO methodology, other authors do explicitly define the functional unit and system boundaries [30, 82, 87, 93, 94].

3.2.1. Economic Criteria. Out of the 83 reviewed manuscripts, only 7 do not consider economic criteria in their sustainability assessments. Among the rest, three main 


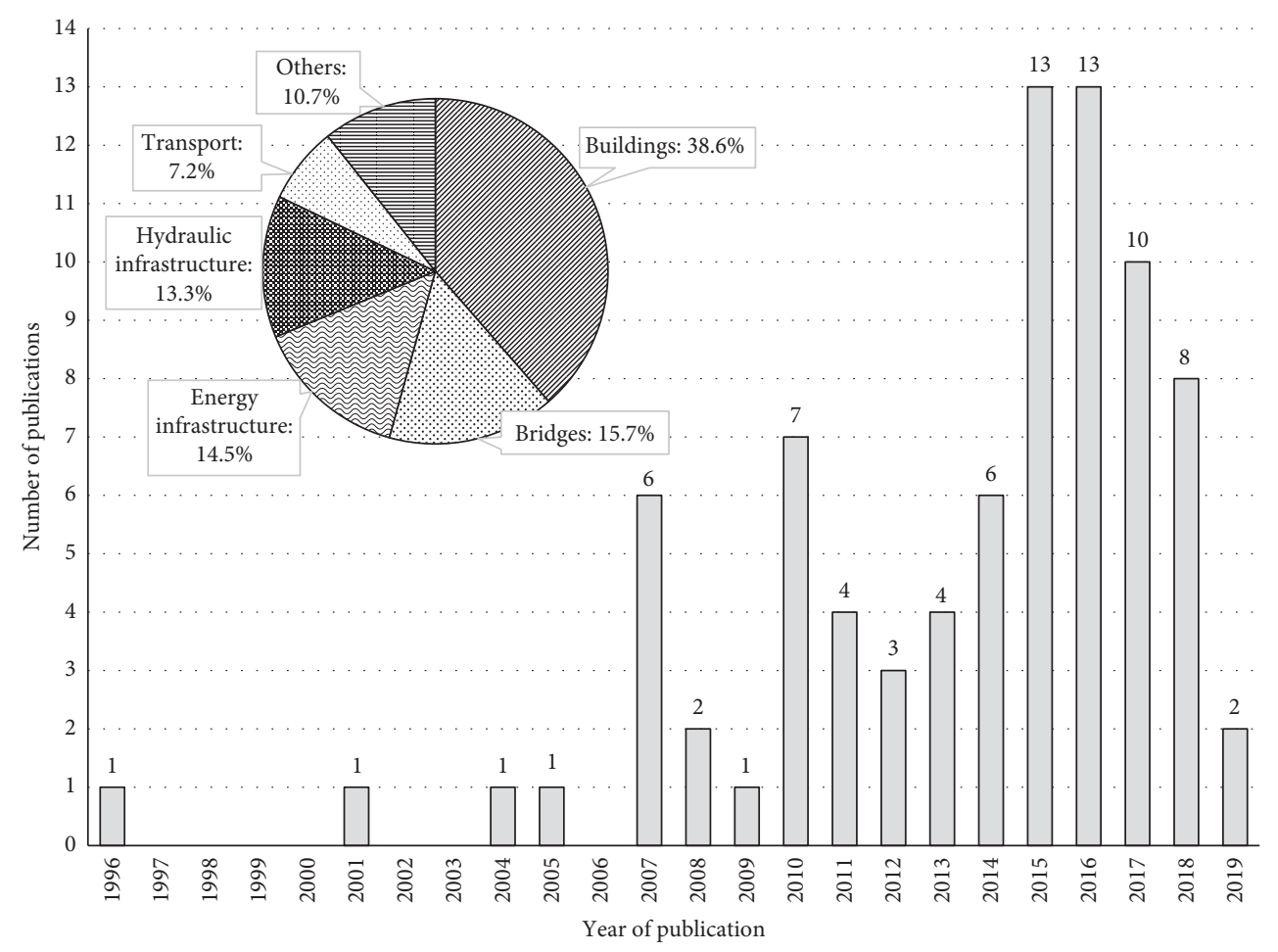

Figure 2: Distribution of contributions per year (1996-2019).

economic impacts have been identified, namely, the construction or implementation costs, the costs derived from maintenance and operation of the infrastructure, and the costs resulting from the end of life stage. Table 1 presents the main economic indicators considered in the reviewed studies. $94.7 \%$ of the reviewed papers that take into account the economic dimension of sustainability assume the costs derived from the installation of the infrastructure relevant in the assessment. Only $13.3 \%$ of the reviewed papers consider the direct costs associated with the disposal of the infrastructure in their assessments and $63.9 \%$ the costs of the maintenance and operation life cycle stage.

It shall be noted that, among the reviewed papers, only 5 explicitly present the assumed discount rates that allow to transform future costs into present currency values. In the field of building design, Mosalam et al. [22] consider a discount rate of 3\%, Jalei et al. [25] assume a discount rate of 5\%, and Perini and Rosasco [24] evaluate three different economic scenarios, with discount rates that range from $4.5 \%$ to $5.5 \%$. Torres-Machí et al. [89], when assessing the sustainability of road pavement treatments, assume a discount rate of 5\%. Klein and Whalley [68] evaluate a cost discounting range that varies from $3 \%$ up to $10 \%$.

3.2.2. Environmental Criteria. Regarding the environmental dimension of sustainability, seven main impact categories have been found to be recurrent in the reviewed studies, namely, emission of pollutants, energy consumption, resources depletion, waste generation, land use, eutrophication, and ozone layer depletion. Table 2 presents the main environmental indicators considered in the reviewed studies for the evaluation of the mentioned criteria.
The emission of pollutants as an indicator of the environmental impact of an infrastructure is the most used criterion within the reviewed papers. It considers the emissions derived from the production of construction materials and construction works, but also from the externalities associated with the construction of infrastructure and its maintenance, such as traffic congestion [61]. While some authors explicitly focus on particular air pollutants, such as carbon dioxide $[24,27,30,57,93], \mathrm{SO}_{2}$ or $\mathrm{NO}_{\mathrm{x}}$ $[64,70]$, or general greenhouse gases $[31,73]$, attention is also paid to pollutants emitted to water [79-81] when dealing with urban water systems.

$46.3 \%$ of the articles include energy consumptions as an additional measure of the environmental impact of an infrastructure. The majority of articles consider the energy needed to produce the construction materials and to construct the particular infrastructure under assessment $[31,34,75]$, while certain authors also consider the energy savings resulting from building envelope designs [24].

The depletion of natural resources is accepted as one of the main consequences of unsustainable construction practices. 32 studies account for the consumption of natural resources into construction materials in their sustainability assessments. Some authors take into consideration the positive environmental impact of using recycled materials $[25,28,88]$ or using potentially reusable ones $[26,33,36,90]$.

Given that the construction industry is considered one of the greatest producers of wastes in a global scale [106], efforts have been made to account their harmful impact in environmental assessments. $25.3 \%$ of the analysed manuscripts take into consideration the generation of waste resulting from the industrial processes involved in the production of 
TABle 1: Main economic criteria and indicators.

\begin{tabular}{llcc}
\hline Economic criteria & Indicator & Assessment & References \\
\hline Installation costs & $€ /$ output unit & Quantitative & {$[19-41,43-50,52-58,61-72,74,75,79-91,93,94,96-99,101]$} \\
Maintenance and & $€ /$ output unit & Quantitative & {$[20-22,24-28,30-34,36-39,41,43,45,52-55,58-61,64$,} \\
operation costs & $€ /$ output unit & Quantitative & $66-69,74,75,79-82,84,86-90,92-98,101]$ \\
Disposal costs & & {$[24-26,30,31,36,43,53,74,75,88]$} \\
\hline
\end{tabular}

TABLE 2: Main environmental criteria and indicators.

\begin{tabular}{|c|c|c|c|}
\hline $\begin{array}{l}\text { Environmental } \\
\text { criteria }\end{array}$ & Indicator & Assessment & References \\
\hline \multirow{7}{*}{$\begin{array}{l}\text { Emission of } \\
\text { pollutants }\end{array}$} & $\mathrm{kg} \mathrm{CO}$ /output unit & Quantitative & $\begin{array}{c}{[19-21,26-28,30,32,34-36,56,64,65,67,68,70,} \\
72,74,75,82,87-90,92-94]\end{array}$ \\
\hline & $\mathrm{kg} \mathrm{SO}_{2}$ /output unit & Quantitative & {$[20,35,64,67,68,70,72,92]$} \\
\hline & kg NOx/output unit & Quantitative & {$[20,35,64,65,67,68,70,72,92]$} \\
\hline & $€ / \mathrm{kg}$ pollutant removed & Quantitative & {$[24]$} \\
\hline & $\begin{array}{l}\text { Costs of medical care needs } \\
\text { due to pollution }(€)\end{array}$ & Quantitative & {$[61]$} \\
\hline & $\begin{array}{l}\text { Oxygen, nitrogen, and phosphates } \\
\text { emitted to water }\end{array}$ & Quantitative & {$[80]$} \\
\hline & Assessment by experts through point scale & Qualitative & $\begin{array}{c}{[23,25,29,31,33,38,39,41,43,45,52,54,55} \\
58-60,62,63,66,69,71,73,78,81,83,85,91, \\
95,97,98,100,101]\end{array}$ \\
\hline \multirow{4}{*}{ Energy consumption } & MJ (MWh)/output unit & Quantitative & $\begin{array}{c}{[19,20,26-28,30,32,34-36,72,74} \\
75,82,87,88,90,93,94]\end{array}$ \\
\hline & $€ /$ year/output unit & Quantitative & {$[24]$} \\
\hline & Tonnes of oil equivalent (TOE) & Quantitative & {$[99]$} \\
\hline & Assessment by experts through point scale & Qualitative & {$[25,29,31,33,38-40,42,45,73,95,101]$} \\
\hline \multirow{2}{*}{$\begin{array}{l}\text { Raw material } \\
\text { consumption }\end{array}$} & Consumption/output unit & Quantitative & {$[19-21,26-28,35,68,72,74,75,87,88,90,93,94]$} \\
\hline & Assessment by experts through point scale & Qualitative & {$[25,31,33,38-40,42,43,45,82,96,98]$} \\
\hline \multirow{2}{*}{ Waste generation } & $\mathrm{kg} /$ output unit & Quantitative & {$[26,32,35,72,87]$} \\
\hline & Assessment by experts through point scale & Qualitative & {$[29,31,33,38,39,42,43,45,95,96,98,100]$} \\
\hline \multirow{3}{*}{ Land use } & $\mathrm{m}^{2} /$ output unit & & {$[68]$} \\
\hline & Assessment by experts through point scale & Qualitative & $\begin{array}{c}{[24,28,29,38,39,42,45,51,55,66,69,71,73} \\
77,78,91,96,98]\end{array}$ \\
\hline & $\begin{array}{l}\text { Aquatic ecotoxicity, salinity, } \\
\text { biological indices }\end{array}$ & Quantitative & {$[70,79,80]$} \\
\hline \multirow{2}{*}{ Eutrophication } & kg phosphate/output unit & Quantitative & {$[35,36,70,72,90]$} \\
\hline & Assessment by experts through point scale & Qualitative & {$[42,77,78,98]$} \\
\hline \multirow[t]{2}{*}{ Ozone depletion } & $\begin{array}{c}\text { kg CFC (Chlorofluorocarbons)/ } \\
\text { output unit }\end{array}$ & Quantitative & {$[34-36,70,72,90]$} \\
\hline & Assessment by experts through point scale & Qualitative & {$[33,42]$} \\
\hline
\end{tabular}

construction materials or from the demolition works. Consideration is given to both solid wastes from construction materials $[22,26]$ and water wastes [86].

Land use is an environmental concept that implies both land occupation and transformation of land. Land use derived from the construction of infrastructures results in damage to ecosystems and loss of biodiversity. From the 83 reviewed articles, 25 (30.1\%) take land use into account as an indicator of the environmental damage derived from infrastructures. The effects of land use have been accounted for as local ecosystem disturbances [96], destruction of wildlife habitats $[45,91]$, proximity to migratory paths [71], and effects on biodiversity [28, 70]. Given the particular scope of their study, Perini and Rosasco [24] consider the creation of habitats.

Eutrophication is the consequence of the emission of particular pollutants, mainly phosphate, derived from human activities to water, promoting an uncontrolled growth of algae that shall compromise the survival of other water species. This environmental impact has been considered by nine articles ( $10.8 \%$ of total).

Ozone layer is essential for life, as it hinders harmful solar ultraviolet radiation. Ozone layer depletion because of the emission of substances containing chlorine and bromine atoms has been accounted in eight studies as an additional indicator capable of measuring the environmental damage derived from infrastructures and their associated activities.

3.2.3. Social Criteria. Regarding the social dimension of sustainability, the criteria assessed in the studies reviewed shall be grouped into eight main categories, namely, social wellbeing, aesthetics, job creation, development of local economies, externalities, innovation, culture, and health. Table 3 presents the main social indicators considered in the reviewed studies for the evaluation of the mentioned criteria. 
TABLE 3: Main social criteria and indicators.

\begin{tabular}{|c|c|c|c|}
\hline Social criteria & Indicator & Assessment & References \\
\hline \multirow{4}{*}{ Social wellbeing } & Increase of income of local population ( $€$ /year) & Quantitative & {$[48,49]$} \\
\hline & Assessment by experts through point scale & Qualitative & {$[25,28,29,31,36,39-41,45,66$} \\
\hline & Habitability increase $\left(\mathrm{m}^{2}\right)$ & Ouantitative & $69,71,73,77,78,81,88,91,98,101]$ \\
\hline & Comfort (hours/year) & Quantitative & {$[30]$} \\
\hline Aesthetics & Assessment by experts through point scale & Qualitative & $\begin{array}{c}{[23-25,27,31,33,38,40,42,43,51,52,54,} \\
55,58,62,63,67,71,75,77,81,88,96-98]\end{array}$ \\
\hline \multirow{5}{*}{ Job creation } & Hours of work/output unit & Quantitative & {$[64,65,68,70,87]$} \\
\hline & Gross value added/hour worked & Quantitative & [99] \\
\hline & Unemployment rate & Quantitative & {$[96]$} \\
\hline & Employment increase (\%) & Quantitative & {$[48,49]$} \\
\hline & Assessment by experts through point scale & Qualitative & {$[45,66,69,73,77]$} \\
\hline \multirow{3}{*}{$\begin{array}{l}\text { Development of } \\
\text { local economies }\end{array}$} & GDP increase $(€)$ & Quantitative & {$[48,49,99]$} \\
\hline & Land value degradation $\left(€ / \mathrm{m}^{2}\right)$ & Quantitative & {$[96]$} \\
\hline & Assessment by experts through point scale & Qualitative & {$[31,33,45,67,71,73,77,78,98]$} \\
\hline \multirow{4}{*}{ Externalities } & Noise pollution $(\mathrm{dB})$ & Quantitative & {$[19,90,92-94,96]$} \\
\hline & Traffic congestion (travel time) & Quantitative & {$[90]$} \\
\hline & Vehicle operating costs $(€)$, user delay costs $(€)$ & Quantitative & {$[53]$} \\
\hline & Assessment by experts through point scale & Qualitative & {$[29,31,39,42,45,51,54,59,60,63,100]$} \\
\hline Innovation & Assessment by experts through point scale & Qualitative & {$[38-40,45,75,98]$} \\
\hline Culture & Assessment by experts through point scale & Qualitative & {$[29,31,38,45,62,71,77,98]$} \\
\hline \multirow{5}{*}{ Health and safety } & \multirow{4}{*}{$\begin{array}{c}\text { Injuries/output unit } \\
\text { Fatalities/output unit } \\
\text { Particulate matter (PM) concentration } \\
(\text { PM2.5/PM10) } \\
\text { Safety costs }(€)\end{array}$} & Quantitative & {$[65,67,87]$} \\
\hline & & Quantitative & {$[68]$} \\
\hline & & Quantitative & {$[36,90]$} \\
\hline & & Quantitative & {$[53]$} \\
\hline & Assessment by experts through point scale & Qualitative & $\begin{array}{c}{[19,21,29,31-33,39,42,43,45,58-60,75} \\
77,82,85,88,91,93,94,97,98,100,101]\end{array}$ \\
\hline
\end{tabular}

The impact of an infrastructure on the social wellbeing is included in 34 manuscripts (41\% of total) and combines aspects such as public acceptance $[31,50,66,69,70,101]$, social welfare and income increase [48, 71, 73, 81], accessibility [78, 79, 86], or leisure [76]. Assessments focused on building and road pavement design also account for the comfort of the users [26, 27, 30, 45, 88, 92].

Aesthetics has also been identified as a main indicator for social sustainability, which is closely related to social acceptance of the project. The aesthetic, which has been assessed in 26 articles, includes not only the aesthetical perception of the infrastructure itself, but also its integration with the urban $[43,50]$ or rural environment $[48,49]$.

Direct and indirect working opportunities derived from the construction and maintenance of an infrastructure have been considered in 16 studies (19.3\% of total), which is closely related to an increase of the social welfare. Although the methodological sheets for social life cycle assessments developed by UNEP/SETAC [107] give preference not to the generated employment in general, but to that generated for the local communities, it is common practice in social life cycle assessments to use the generated employment in general terms as an indicator of social sustainability [104, 108].

16 studies take into consideration the effects of an infrastructure on the local development of a region, resulting from both the construction and maintenance activities, as well as from the serviceability provided by the infrastructure. Aspects such as the increase of the Gross Domestic Product
$[49,99]$, the increase in tourism $[77,78]$ or the regional economic benefits derived from the use of local materials and resources [26, 33, 70, 98] have been included in this social impact category.

Externalities derived from infrastructure construction and, mainly, from infrastructure maintenance have been considered in $33.7 \%$ of the reviewed studies. Effects such as traffic disruption $[54,60,62,63,90]$ or the increase in vehicle operating costs due to detours $[53,59,61]$ are found to be social indicators recurrently used when assessing the sustainability of bridge infrastructure. Other externalities frequently assessed are noise or dust pollution derived from construction works [22, 45].

The inclusion of innovative concepts in the infrastructure design is also accounted for as a social indicator, as it seeks to ensure the progress and technological development of the society. 9 articles have taken such aspect into account. The evaluation of this impact is based either on a binary indicator, which scores 1 if the design includes patented materials or solutions $[22,74,75]$ or relies on the knowledge of the chosen panel of experts [37, 40].

$13.3 \%$ of the reviewed manuscripts include culture as a measure of social sustainability, paying special attention to the respect for the cultural heritage of a region $[29,31,37,38,45,62]$, or for its traditional architecture [26]. Given the difficulties to quantitatively assess cultural indicators [107], most authors rely on the knowledge of the chosen panel of experts for the evaluation of cultural impacts $[45,71,77]$. 
Health and safety include both the practices of construction and industry companies to protect the lives of their workers, but also the risk of accidents for users of an infrastructure. The impact of the activities associated with the construction and maintenance of an infrastructure on the safety of the involved workers, as well as the risks to the health of the users of the infrastructures, has been considered in 42 articles (50.6\% of total).

3.3. Treatment of Qualitative Data. Once the indicators are selected that properly characterise the problem and condition the decision, the following step in a multicriteria decision-making problem consists in transforming them into quantitative values. While the numerical assessment of quantitative variables is straightforward, handling with qualitative criteria requires a certain preprocessing so as to transform such values into numerical ones. When dealing with qualitative criteria, such as aesthetics or comfort, many studies require the experts to evaluate such variables by assigning them scores on different scales ranging from 0 to 1 , or from 0 to 10 in the most of the reviewed cases $[28,50,52,81,101]$.

In other cases, experts are required to evaluate qualitative criteria by choosing one of the different answer options provided by the decision maker in a closed form, which are then directly related to specific numerical values. This approach is often preferred when dealing with complex problems, where experts find it easier to reflect their judgements in linguistic terms rather than in the form of precise numbers. For example, Gumus et al. [73] base the evaluation of each of the criteria assumed for the assessment of wind power plants on the mentioned translation of linguistic variables into numerical values. De la Fuente et al. [82] require experts to evaluate linguistically different functional and social aspects related to sewerage systems, such as surface degradation, risk of accidents, and the affection of pollutants and construction time on the wellbeing of the population. The use of linguistic variables has been used by $[93,94]$ when assessing the risks derived from handling and installing precast tunnel segments. Heravi et al. [45] also use a similar approach when handling the attitudes of experts towards different types of risks when establishing their judgements. Similar approaches have been conducted in other studies $[34,40,54,66,67,100]$. Samani et al. [35] use the PROMETHEE usual preference function to transform linguistic variables into numerical values.

Kripka et al. [57] use the AHP method based on Saaty's fundamental scale to determine a normalised score for each of the qualitative criteria considered in the sustainability assessment, namely, architectural value and security sensation. Other studies also base the scoring of qualitative data on such approach, such as $[55,60,62]$.

3.4. Normalisation of the Indicators. When dealing with indicators that are measured in different units, and prior to proceed to their aggregation into a final score, indicator values shall be normalised into dimensionless, comparable values. The most basic normalisation technique used is the so-called linear normalisation and consists in dividing the indicator value $x_{i j}$ of a particular alternative $i$ associated with criterion $j$ by the sum of the indicator values related to the complete set of alternatives:

$$
\bar{x}_{i j}=\frac{x_{i j}}{\sum_{i} x_{i j}} .
$$

Such approach is followed by the vast majority of studies reviewed [25, 29, 30, 34, 38-41, 47, 48, 52, 70, 89, 95]. When the decision-making problem involves the simultaneous consideration of both criteria with maximising and minimising optimal values, indicators are then normalised on the basis of the preferable optimum for each of them:

$$
\begin{aligned}
& \bar{x}_{i j}=\frac{x_{i j}}{\max _{i}\left\{x_{i j}\right\}}, \quad \text { where } \max _{i}\left\{x_{i j}\right\} \text { is preferred, } \\
& \bar{x}_{i j}=\frac{\min _{i}\left\{x_{i j}\right\}}{x_{i j}}, \quad \text { where } \min _{i}\left\{x_{i j}\right\} \text { is preferred. }
\end{aligned}
$$

Such approach is followed by $[23,28,51,101]$. This normalisation technique based on the preferred optimum of each criterion has been extended into the so-called Weitendorf's linear normalisation, so as to take into consideration their distance to the worst value $[68,77,85]$ :

$$
\begin{aligned}
& \bar{x}_{i j}=\frac{x_{i j}-x_{\min }}{x_{\max }-x_{\min }}, \text { for maximising optima, } \\
& \bar{x}_{i j}=\frac{x_{\max }-x_{i j}}{x_{\max }-x_{\min }}, \text { for minimising optima. }
\end{aligned}
$$

Other studies, such as $[31,36,73,81,86,87]$, normalise the values of the decision variables by using a vector normalisation technique, where each element $x_{i j}$ of the decision matrix is normalised by dividing it by its norm:

$$
\bar{x}_{i j}=\frac{x_{i j}}{\sqrt{\sum_{i} x_{i j}^{2}}} \text {. }
$$

Particular value functions have been also used to normalise the indicator values into dimensionless values. So, studies based on the Simple Additive Weighting technique called MIVES $[19,21,26,32,42-44,50,67,74,75$, $82,88,92-94,100]$ use exponential value functions defined as:

$$
\bar{x}_{i j}=\left[1-e^{-K_{i}\left(\left(x_{i j}-x_{\mathrm{opt}}\right) / c_{i}\right)^{P_{i}}}\right] \cdot\left[1-e^{-K_{i}\left(\left(x_{\mathrm{opt}}-x_{i j}\right) / c_{i}\right)^{P_{i}}}\right],
$$

where $x_{\mathrm{opt}}$ is the least preferable value of the indicator under evaluation, $P_{i}$ is a shape factor that makes the value function be concave, linear, convex, or S-shaped, $C_{i}$ is the curve's inflexion point, and $K_{i}$ tends towards $x_{i j}$ at the inflexion point.

The aggregation technique PROMETHEE also bases the normalisation step on the construction of preference functions. Vincke and Brans [109] proposed six basic types of preference functions. Depending on the nature of the criteria 
to be assessed, different value functions shall be used. For example, Balali et al. [54] combine the use of V-shaped preference functions and linear preference functions. Samani et al. [35] use the usual preference function for qualitative criteria and the $\mathrm{V}$-shaped function for the quantitative ones. Other preference functions such as exponential functions $[53,69,76]$ are also used. One of the main advantages of using such exponential functions is that they are continuously defined and consequently easier to use when compared to the other discrete, stepped preference functions.

Finally, it shall be highlighted that the normalisation of indicator values only makes sense when the involved indicators are measured in different units. Thus, those studies based on the qualitative criteria assessment of experts, who set scores for each criterion based on their expertise $[60,62,78]$, do not require such normalisation step prior to their aggregation.

3.5. Weighting Techniques. Weighting the criteria is an essential step in a decision-making process, as it will condition the results of an assessment. Figure 3 shows the weighting methods identified among the reviewed publications, as well as the number of times that each one has been applied. By far, the Analytic Hierarchy Process (AHP) is the most used method to determine the weights of the criteria considered in a decision-making process, used by $65.1 \%$ of the authors. This widely used method allows to transform, through a systematic procedure, the pairwise judgements emitted by a single or a group of decision makers into a relevance score, which will be used in the later assessment of the impacts. No particular relationship has been identified between the use of this weighting technique and either the year of publication or the type of infrastructure assessed.

The direct allocation of weights has been identified as the second most used method (16 papers, $19.3 \%$ of the publications). By using this technique, the evaluator directly sets the score that represents the importance of each criterion on the decision-making problem. Shanon entropy methods are used to provide weightings less based on the subjectivity inherent in the previously mentioned techniques by measuring the uncertainty associated with the provided judgements [23, 25, 54, 73, 87]. Similar results have been previously reported regarding the application frequency of AHP, direct allocation, and entropy methods in relation to the social sustainability of infrastructures [17].

At last, three other techniques have been marginally used, namely, the Best-Worst method (BWM) [41], the Quality Function Deployment (QFD) [40, 51], and the SWARA method [29] to assess the sustainability criteria weights. While the methodology related to the Best-Worst technique is close to the AHP, the Quality Function Deployment method has been used as a means to handle with complex and conflicting criteria, such as those describing sustainability, which can often be difficult to assess by decision makers. SWARA method is a so-called order relation technique based on the direct assignation of criteria relevance by a group of experts. It shall be noted that 4

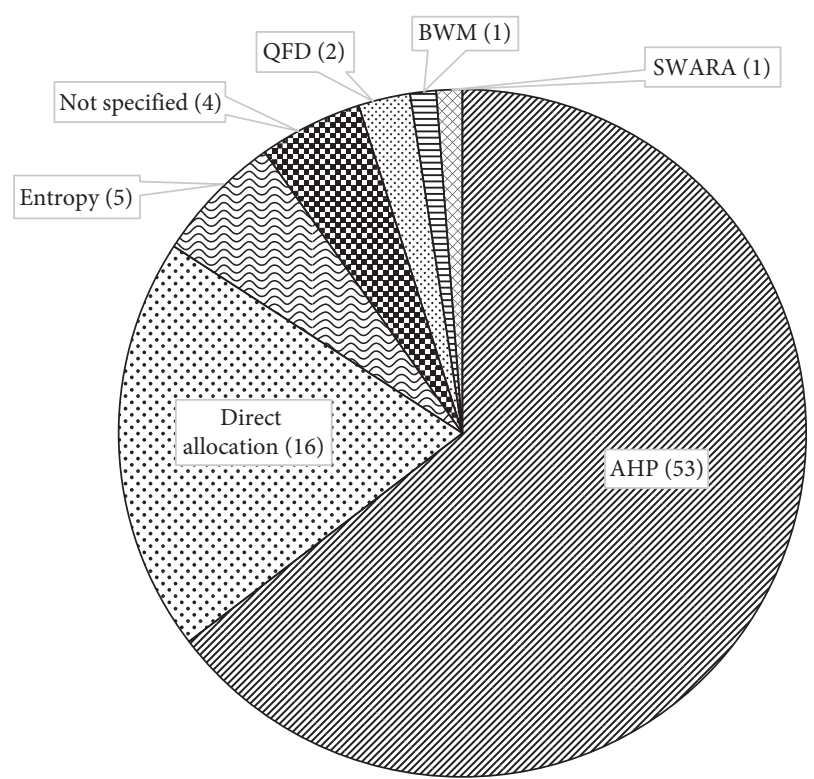

FIGURE 3: Weighting techniques applied within the reviewed papers.

contributions do not explicitly report the methodology used in the criteria weights assignation.

3.6. Aggregation of Indicators. Once the relevance of each criterion is established, the next step in a decision-making process is to assess the obtained results. Figure 4 shows the frequency of use of the multicriteria assessment techniques applied in the reviewed contributions, as well as the specific infrastructure field in which they have been applied. The most frequently used technique is the Simple Additive Weighting (SAW) or direct aggregation of the criteria [110], which has been applied by 43 publications (51.8\% of total). The popularity of this technique is based on its ease of application, as it consists in the simple addition of the normalised criteria scores weighted by their corresponding relevance factors obtained in a previous step. SAW is a compensatory technique that is revealed as a very intuitive tool for decision makers, based on an extremely simple and transparent calculation procedure. However, SAW is limited by the fact that it can only deal with maximising, positive defined criteria [111]. Minimising criteria should be properly converted to maximising ones before being used. Similar conversions should be applied to negative defined criteria. The results of the assessments using SAW technique depend therefore on the transformation applied [111].

Thus, to overcome such limitations when handling with more complex criteria, other MCDM methods are used. Among them, the most applied one is TOPSIS (Technique for Order Preference by Similarity to Ideal Solution), used by $15.7 \%$ (13 studies) of the reviewed papers. TOPSIS allows to rank different alternatives in a multicriteria context, considering the fact that the most preferred solution should have the shortest geometric 

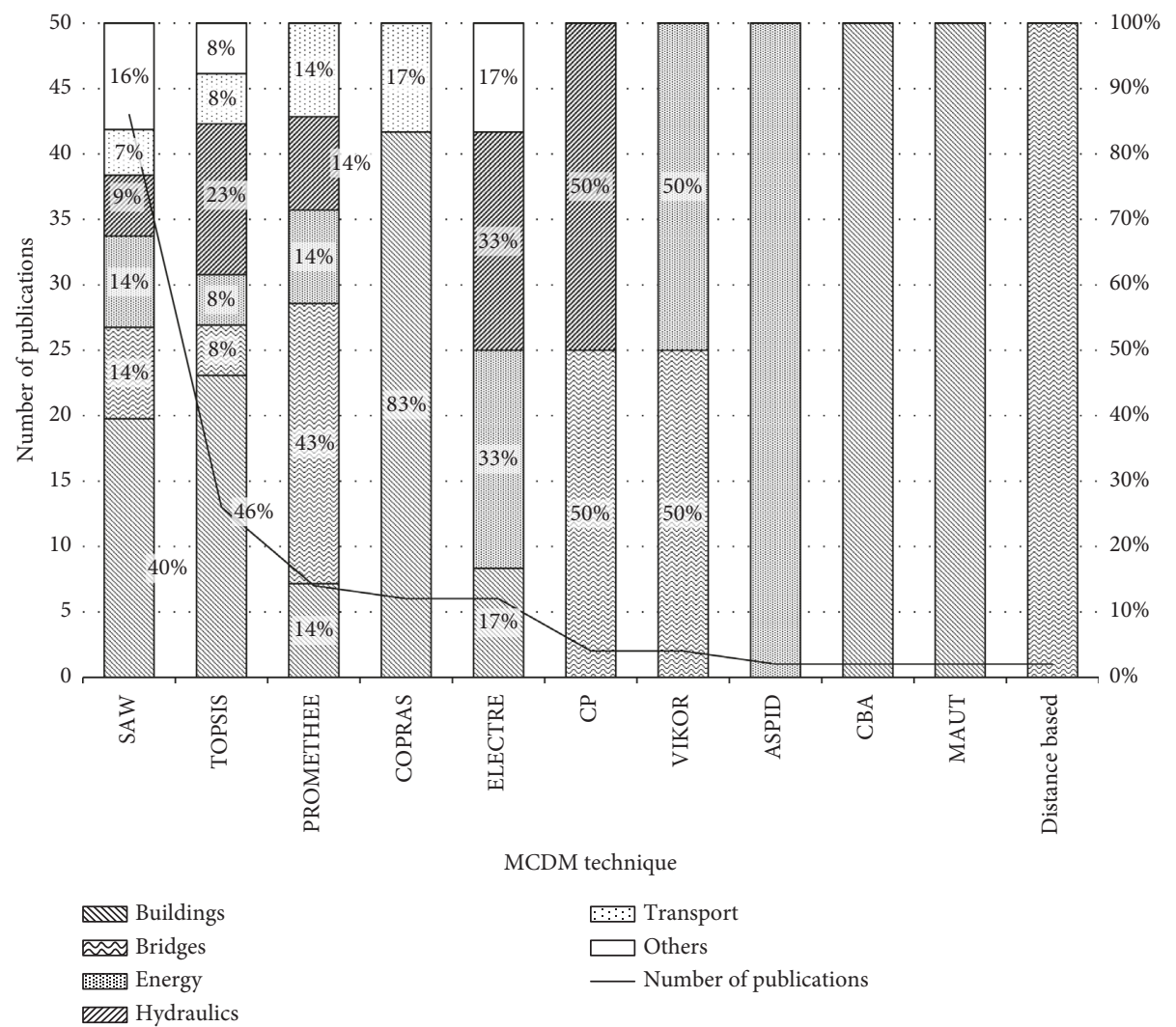

Figure 4: MCDM assessment techniques applied within the reviewed papers.

distance to the positive ideal solution and the longest distance to the less preferred solution [112]. TOPSIS is based on a simple, comprehensible concept that aims to represent the rationale of human decision processes [113]. Its high flexibility to accommodate to further extensions based on fuzzy sets or grey theory, for example, and its computational efficiency are additionally recognised advantages of this method [114]. Transparency along the decision-making process is revealed as an essential requirement when choosing an adequate MCDM method [115]. The traceability of the analysis, i.e., the ability to investigate into the different analysis steps to identify strengths and weaknesses of each alternative under evaluation, is considered as a main source to provide argumentation in a decision-making process. The transparency associated with TOPSIS is one of the main advantages of this technique [114].

PROMETHEE has been applied in $8.4 \%$ of the papers reviewed. This outranking method has suffered different modifications over the course of time, so as to overcome some of its initial limitations. PROMETHEE III, for example, does not even require the variables to be normalised and is applicable when information is missing [116]. However, PROMETHEE techniques are recognised to be very time consuming and not intuitive, making it often difficult to keep an overview over the problem when a significant number of criteria are involved [117]. In addition, in some cases, the ranking of alternatives can drastically change and even reverse when a new alternative is introduced [53], which is one of the main disadvantages of these techniques.

$7.2 \%$ of the studies reviewed use ELECTRE in their assessments. ELECTRE is another outranking technique based on concordance analysis. This noncompensatory method is particularly useful when ordinal scales are used to measure criteria [86]. It has the ability to include vagueness and uncertainty in the assessments, but, as with PROMETHEE, outcomes can be hard to explain [111]. As the outcomes are provided as an ordinal ranking, ELECTRE does not allow the decision makers to identify the particular strengths and weaknesses of the assessed alternatives, or even determine how much better an alternative is over the rest [118]. One of the advantages of ELECTRE methods is that, in contrast to PROMETHEE techniques, they do not rely on the selection or construction of appropriate utility functions by the decision makers, which are not always straightforward and may condition the assessment results.

COPRAS has also turned out to be one of the most used techniques in sustainability assessment of infrastructures. As ELECTRE method, COPRAS has been applied in $7.2 \%$ of the papers reviewed. COPRAS is recognised to be simple to calculate and, in contrast with SAW, adequate when dealing with both maximising and minimising criteria values [119]. Other MCDM techniques, such as Cost-Benefit Analysis (CBA) [24], Compromise Programming (CP) [61, 84], Multiattribute Utility Theory (MAUT) [22], Analysis and Synthesis of Parameters under Information Deficiency (ASPID) [64], Distance-Based methods [56], and VIKOR 
technique $[57,66]$, have been marginally applied to assess the sustainability of particular infrastructure designs. Although no systematic relationship is found between the MCDM method applied and the field of assessment or the weighting method used, it is interesting to note that five out of the six publications using COPRAS are focused on the sustainability evaluation of buildings.

It shall be noted that the proportions found in the present review regarding the use of MCDM techniques for the sustainability assessment of infrastructures have also been found in other fields of application. As an example, Kaya et al. [120] report that $44 \%$ of the studies dealing with the assessment of energy policies use SAW technique, 23\% TOPSIS, 8\% PROMETHEE, and 6\% ELECTRE, results that are quite similar to the ones obtained in the present review. Likewise, Mardani et al. [121] focus on the use of MCDM techniques to solve management problems associated with construction, risk, and safety and report that $33 \%$ of the reviewed studies use SAW, 11\% TOPSIS, 8\% ELECTRE, and 6\% PROMETHEE. Similar results are reported by other studies, dealing with application fields such as mining and mineral processing [122].

Besides SAW, TOPSIS is revealed as the most used method to assess MCDM problems in different fields, such as supplier selection [123], manufacturing and product recovery [124], supply chain management [125], or material selection in the automotive industry [126], just to cite some examples. After analysing the use of MCDM in other fields of application, it shall be concluded that the trends detected in the field of sustainability assessment of infrastructures are quite similar to those popular in other fields.

3.7. Sensitivity Analysis. An important step in MCDM problems is to perform sensitivity analyses on those aspects that might alter significantly the conclusions of the assessment, so as to ensure the consistency of the final decision. From the total of the reviewed studies, only $18(21.7 \%)$ include a sensitivity analysis in their assessments.

The majority of them (13 out of 18 manuscripts) focus their attention on the results sensitivity against the chosen criteria weights. This evidences that the weighting is considered as a great source of uncertainty in MCDM problems, usually derived from the subjectivity inherent to weighting based on experts' judgements [127]. The nonprobabilistic uncertainty introduced in MCDM problems through experts' opinions is greater the more complex is the problem. So, when dealing with sustainability assessments, where criteria are often conflicting and usually of very different nature, decision makers might be unable to provide precise judgements and become overwhelmed by the problem to be assessed.

The usual way to proceed is to make one of the involved decision criteria predominant with respect to the rest and compare the results with the ones obtained after the conventional weighting [21, 28, 67, 77, 82, 93-95]. This allows the decision makers identify those criteria where the subjectivity is greater and is therefore more sensitive to experts' biases. Mosalam et al. [22] analyse different weighting scenarios where the weighting of one of the criteria is changed continuously, from $0 \%$ to $100 \%$. By doing so, the decision maker is able to determine for which weights the results are more prone to change and check if the weights obtained in his/her analysis are close to such thresholds or not.

Ignatius et al. [40] and Heravi et al. [45] perform a sensitivity analysis on the power assigned to each of the involved experts in the decision-making problem. Several authors also focus on the sensitivity that the obtained results have on the parameters defining the aggregation techniques that they are using. So, Gervásio and Da Silva [53] evaluate the sensitivity of the results on the PROMETHEE preference function used to normalise the indicator values. In addition, a second sensitivity analysis is also conducted on the criteria weights. Similarly, Martin et al. [79] conduct a sensitivity analysis not only on the criteria weights, but on the selected indifference, preference, and veto thresholds assumed when using the ELECTRE method.

3.8. Dealing with the Experts' Subjectivity. MCDM problems have a highly subjective component, since they are generally based on the cognitive capacity of the decision makers, who are usually required to provide the relevance of each criterion and even to assign performance values to the selected criteria indicators, as derived from the results shown in the present literature review. However, during the application of the described steps inherent in a decision-making process, it is common practice to handle with so-called crisp or bivalued data. This is proved by $72.3 \%$ of the analysed manuscripts (60 papers), as shown in Figure 5. Such crisp approach to MCDM problems presumes the information provided by the judgements emitted by the decision makers to be absolutely precise and certain and has been therefore subject to strong criticism for not being able to reflect the vague and qualitative nature of human thinking [128]. So, when dealing with complex problems such as sustainability assessments, with criteria that are usually conflicting and only difficultly to be compared, neglecting the fuzziness of human thinking may lead to erroneous conclusions [128]. So as to deal with the mentioned nonprobabilistic uncertainties associated with human thinking, efforts have been made by several authors to apply different mathematical approaches to deal with the information resulting from the judgements of the decision makers. So, since 2007, 17 manuscripts (20.5\% of total) have been found to apply the fuzzy sets theory [129] in the MCDM process for the sustainability assessment of infrastructures combined with a variety of weighting and MCDM techniques (AHP, TOPSIS, VIKOR, SAW, PROMETHEE, ELECTRE, and COPRAS). As an alternative, grey numbers have been recently applied by Heravi et al. [45] in the assessment of the sustainability of industrial buildings.

The fuzzy theory was further developed by Atanassov [130] into the intuitionistic fuzzy sets theory, which has been used in sustainability MCDM assessments of infrastructures only since 2013 [63, 69, 73, 87]. At present, the intuitionistic approach has been further generalised into the neutrosophic sets 


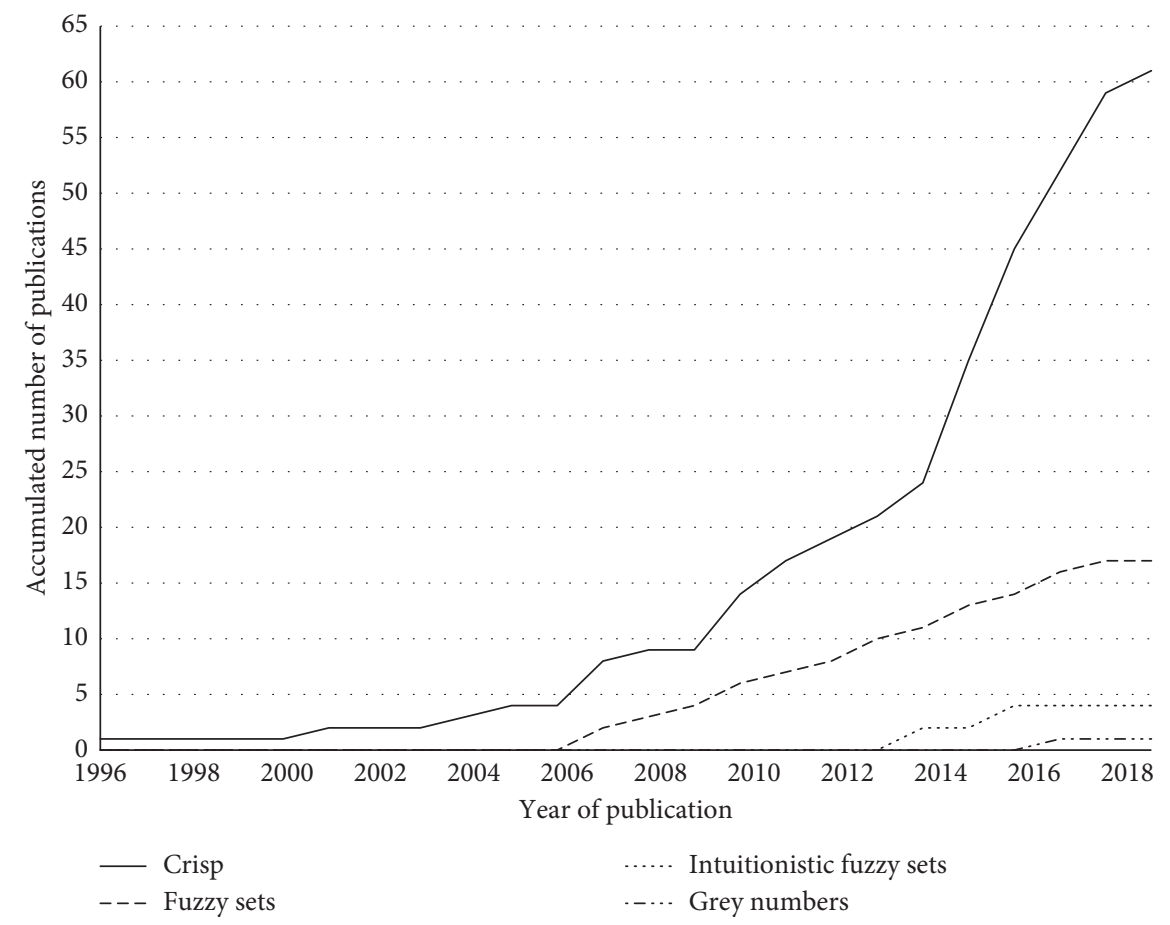

FIGURE 5: Handling of linguistic variables within the reviewed papers.

approach, developed by Smarandache in 1999 [131]. No application of the neutrosophic approach has yet been found to be applied in MCDM related to the infrastructure assessment.

\section{Conclusions}

This study presents a systematic literature review on the sustainability assessment of infrastructure projects and designs developed by means of MCDM techniques. Given the complex characterisation of sustainability, MCDM is revealed as a useful tool to integrate decision criteria related to the different dimensions of sustainability, namely, economy, environment, and society. MCDM has gained relevance to evaluate sustainability mainly since 2015 , when the Sustainable Development Goals were set by the United Nations. In particular, MCDM has been found to be mainly applied for the assessment of buildings (38.6\%), bridges $(15.7 \%)$, energy infrastructure $(14.5 \%)$, hydraulic infrastructure (13.3\%), and transport infrastructure (7.2\%). In view of the results, more efforts should be put in the sustainability analysis of infrastructures where long-lasting, intergenerational service lives are required, such as bridges or dams. In those cases, where the required service life frequently exceeds 100 years, and where the magnitude of the impacts is not negligible given the dimensions of the infrastructures and their material and maintenance demands, evaluating the sustainability throughout their life cycle acquires an essential relevance.

AHP is revealed as the most used weighting technique to identify the relevance of the decision criteria, being applied in $65.1 \%$ of the analysed studies. Regarding the assessment technique used to evaluate the final sustainability scores of the design alternatives under consideration, SAW has resulted to be by far the preferred option, used by $51.8 \%$ of the authors. This technique, despite its undoubted advantages, such as its ease of use, is limited by the fact that it can only deal with positive defined, maximising criteria. Given the complex relations between sustainability criteria, and their often conflicting nature, other techniques have been used by the scientific community, being TOPSIS the most applied (15.7\% of the contributions).

Regarding the mathematical handling of the linguistic variables involved in MCDM process, where the main variables to derive the criteria weights are usually the judgements and opinion of experts, it has been found that the vast majority of manuscripts assume a crisp approach. It is first since 2007 when authors have started to implement the fuzziness of human judgements into the decision-making process. Although fuzzy sets theory, and to some extent even intuitionistic fuzzy sets theory, have been applied in the sustainability assessment of infrastructures, the recently developed and more generalised neutrosophic sets have not been used to date for such purpose.

Regarding the criteria considered in the assessments, it shall be said that $74.7 \%$ base their definition on the framework of the life cycle of the infrastructure, which is in good accordance with the temporal dimension of sustainability. However, although recognised standards exist that provide guidelines for coherent and robust life cycle analyses, it has been found that only $4.8 \%$ of the publications base their studies on such standards, properly defining basic concepts such as the functional unit or the system boundaries assumed in the evaluation. It shall also be noted that none of the studies base the definition of the social criteria and indicators on the "Guidelines for social life cycle assessment of products," 
which provides, at present, the most recognised methodology to perform social life cycle assessments. With regard to life cycle costing, only $6.1 \%$ of the authors take into consideration the discounting of costs related to time.

In view of the obtained review results, further research is required to integrate the existing life cycle impact assessment methodologies (economic, environmental, and social) into the multicriteria sustainability assessment of infrastructures, so as to provide robust and integral assessment tools based on a universal, systematic, and transparent methodology. In addition, further efforts should be made to consider the fuzziness of experts' judgements in future assessment models.

\section{Conflicts of Interest}

The authors declare that there are no conflicts of interest regarding the publication of this paper.

\section{Acknowledgments}

The authors acknowledge the financial support of the Spanish Ministry of Economy and Competitiveness, along with FEDER funding (Project no. BIA2017-85098-R).

\section{References}

[1] J.-H. Choi, "Strategy for reducing carbon dioxide emissions from maintenance and rehabilitation of highway pavement," Journal of Cleaner Production, vol. 209, pp. 88-100, 2019.

[2] J. Olivier, G. Janssens-Maenhout, M. Muntean, and J. Peters, "Trends in global CO2 emissions: 2016 report," PBL Netherlands Environmental Assessment Agency, The Hague, Netherlands, 2016.

[3] A. P. Kyriacou, L. Muinelo-Gallo, and O. Roca-Sagalés, "The efficiency of transport infrastructure investment and the role of government quality: an empirical analysis," Transport Policy, vol. 74, pp. 93-102, 2019.

[4] T. García-Segura, V. Yepes, J. V. Alcalá, and J. Alcalá, "Optimization of concrete I-beams using a new hybrid glowworm swarm algorithm," Latin American Journal of Solids and Structures, vol. 11, no. 7, pp. 1190-1205, 2014.

[5] V. Yepes, J. V. Martí, T. García-Segura, and F. GonzálezVidosa, "Heuristics in optimal detailed design of precast road bridges," Archives of Civil and Mechanical Engineering, vol. 17 , no. 4 , pp. 738-749, 2017.

[6] D. M. Frangopol, "Life-cycle performance, management, and optimisation of structural systems under uncertainty: accomplishments and challenges1," Structure and Infrastructure Engineering, vol. 7, no. 6, pp. 389-413, 2011.

[7] M. Safi, H. Sundquist, and R. Karoumi, "Cost-efficient procurement of bridge infrastructures by incorporating life-cycle cost analysis with bridge management systems," Journal of Bridge Engineering, vol. 20, no. 6, 2015.

[8] I. J. Navarro, V. Yepes, J. V. González-Vidosa, and F. GonzálezVidosa, "Life cycle impact assessment of corrosion preventive designs applied to prestressed concrete bridge decks," Journal of Cleaner Production, vol. 196, pp. 698-713, 2018.

[9] Y.-R. Zhang, W.-J. Wu, and Y.-F. Wang, "Bridge life cycle assessment with data uncertainty," International Journal of Life Cycle Assessment, vol. 21, no. 4, pp. 569-576, 2016.

[10] T. García-Segura, V. Penadés-Plà, and V. Yepes, "Sustainable bridge design by metamodel-assisted multi-objective optimization and decision-making under uncertainty," Journal of Cleaner Production, vol. 202, pp. 904-915, 2018.

[11] P. Van den Heede and N. De Belie, "A service life based global warming potential for high-volume fly ash concrete exposed to carbonation," Construction and Building Materials, vol. 55, pp. 183-193, 2014.

[12] A. M. Braga, J. D. Silvestre, and J. de Brito, "Compared environmental and economic impact from cradle to gate of concrete with natural and recycled coarse aggregates," Journal of Cleaner Production, vol. 162, pp. 529-543, 2017.

[13] M. U. Hossain, C. S. Poon, Y. H. Dong, I. M. C. Lo, and J. C. P. Cheng, "Development of social sustainability assessment method and a comparative case study on assessing recycled construction materials," International Journal of Life Cycle Assessment, vol. 23, no. 8, pp. 1654-1674, 2018.

[14] Y. H. Dong and S. T. Ng, "A social life cycle assessment model for building construction in Hong Kong," International Journal of Life Cycle Assessment, vol. 20, no. 8, pp. 1166-1180, 2015.

[15] L. A. Sierra, V. Yepes, T. García-Segura, and E. Pellicer, "Bayesian network method for decision-making about the social sustainability of infrastructure projects," Journal of Cleaner Production, vol. 176, pp. 521-534, 2018.

[16] L. Montalbán-Domingo, T. García-Segura, M. A. Sanz, and E. Pellicer, "Social sustainability criteria in public-work procurement: an international perspective," Journal of Cleaner Production, vol. 198, pp. 1355-1371, 2018.

[17] I. Zamarrón-Mieza, V. Yepes, and J. M. Moreno-Jiménez, “A systematic review of application of multi-criteria decision analysis for aging-dam management," Journal of Cleaner Production, vol. 147, pp. 217-230, 2017.

[18] L. A. Sierra, V. Yepes, and E. Pellicer, "A review of multicriteria assessment of the social sustainability of infrastructures," Journal of Cleaner Production, vol. 187, pp. 496-513, 2018.

[19] A. Blanco, A. De la Fuente, and A. Aguado, "Sustainability analysis of steel fibre reinforced concrete slabs," in Proceedings of the 2nd International Conference on Concrete Sustainability, Madrid, Spain, June 2016.

[20] B. Reza, R. Sadiq, and K. Hewage, "Sustainability assessment of flooring systems in the city of Tehran: an AHP-based life cycle analysis," Construction and Building Materials, vol. 25, no. 4, pp. 2053-2066, 2011.

[21] O. Pons and A. De la Fuente, "Integrated sustainability assessment method applied to structural concrete columns," Construction and Building Materials, vol. 49, pp. 882-893, 2013.

[22] K. M. Mosalam, U. Alibrandi, H. Lee, and J. Armengou, "Performance-based engineering and multi-criteria decision analysis for sustainable and resilient building design," Structural Safety, vol. 74, pp. 1-13, 2018.

[23] J. Saparauskas, E. K. Zavadskas, and Z. Turskis, "Evaluation of alternative building designs according to the three criteria of optimality," in Proceedings of the 10nd International Conference on Modern Building, structures and Techniques, Vilnius, Lithuania, May 2010.

[24] K. Perini and P. Rosasco, "Cost-benefit analysis for green façades and living wall systems," Building and Environment, vol. 70, pp. 110-121, 2013.

[25] F. Jalaei, A. Jrade, and M. Nassiri, "Integrating decision support system (DSS) and building information modeling (BIM) to optimize the selection of sustainable building components," Journal of Information Technology in Construction, vol. 20, pp. 399-420, 2015. 
[26] G. Gilani, A. Blanco, and A. d. 1. Fuente, "A new sustainability assessment approach based on stakeholder's satisfaction for building façades," Energy Procedia, vol. 115, pp. 50-58, 2017.

[27] Z. Moussavi, A. Akbarnezhad, J. Ferre, and J. Xiao, "Multicriteria selection of façade systems based on sustainability criteria," Building and Environment, vol. 121, pp. 67-78, 2017.

[28] S. Guzmán-Sánchez, D. Jato-Espino, I. Lombillo, and J. M. Diaz-Sarachaga, "Assessment of the contributions of different flat roof types to achieving sustainable development," Building and Environment, vol. 141, pp. 182-192, 2018.

[29] S. Hashemkhani, M. Pourhossein, M. Yazdani, and E. K. Zavadskas, "Evaluating construction projects of hotels based on environmental sustainability with MCDM framework," Alexandria Engineering Journal, vol. 57, no. 1, pp. 357-365, 2018.

[30] A. Invidiata, M. Lavagna, and E. Ghisi, "Selecting design strategies using multi-criteria decision making to improve the sustainability of buildings," Building and Environment, vol. 139, pp. 58-68, 2018.

[31] M. Kamali, K. Hewage, and A. S. Milani, "Life cycle sustainability performance assessment framework for residential modular buildings: aggregated sustainability indices," Building and Environment, vol. 138, pp. 21-41, 2018.

[32] O. Pons and A. Aguado, "Integrated value model for sustainable assessment applied to technologies used to build schools in Catalonia, Spain," Building and Environment, vol. 53, pp. 49-58, 2012.

[33] P. O. Akidari, P. O. Olomolaiye, and E. A. Chintio, "Multicriteria evaluation model for the selection of sustainable materials for building projects," Automation in Construction, vol. 30, pp. 113-125, 2013.

[34] V. Motuziene, A. Rogoza, V. Lapinskiene, and T. Vilutiene, "Construction solutions for energy efficient single-family house based on its life cycle multi-criteria analysis: a case study," Journal of Cleaner production, vol. 112, pp. 532-541, 2016.

[35] P. Samani, A. Mendes, V. Leal, J. Miranda Guedes, and N. Correia, "A sustainability assessment of advanced materials for novel housing solutions," Building and Environment, vol. 92, pp. 182-191, 2015.

[36] F. A. Nassar, R. Ruparathna, G. Chhipi-Shrestha, H. Haider, K. Hewage, and R. Sadiq, "Sustainability assessment framework for low rise commercial buildings: life cycle impact index-based approach," Clean Technologies and Environmental Policy, vol. 18, no. 8, pp. 2579-25910, 2016.

[37] H. Alwaer and D. Clements-Croome, "Key performance indicators (KPIs) and priority setting in using the multiattribute approach for assessing sustainable intelligent buildings," Building and Environment, vol. 45, no. 4, pp. 799-807, 2010.

[38] J. Yu, B. Dang, D. Clements-Croome, and S. Xu, "Sustainability assessment indicators and methodology for intelligent buildings," Advanced Materials Research, vol. 368-373, pp. 3829-3832, 2012

[39] R. Drejeris and A. Kavolynas, "Multi-criteria evaluation of building sustainability behavior," Procedia-Social and Behavioral Sciences, vol. 110, pp. 502-511, 2014.

[40] J. Ignatius, A. Rahman, M. Yazdani, J. Šaparauskas, and S. H. Haron, "An integrated fuzzy ANP-QFD approach for green building assessment," Journal of Civil Engineering and Management, vol. 22, no. 4, pp. 551-563, 2016.
[41] H. Mahdiraji, S. Arzaghi, G. Stauskis, and E. K. Zavadskas, "A hybrid fuzzy BWM-COPRAS method for analyzing key factors of sustainable architecture," Sustainability, vol. 10, no. 5, 1626 pages, 2018.

[42] J. Lombera and I. Aprea, "A system approach to the environmental analysis of industrial buildings," Building and Environment, vol. 45, no. 3, pp. 673-683, 2010.

[43] J. Cuadrado, M. Zubizarreta, E. Rojí, and H. García, "Sustainability-related decision making in industrial buildings: an AHP analysis," Mathematical Problems in Engineering, vol. 2015, Article ID 157129, 13 pages, 2015.

[44] J. Cuadrado, M. Zubizarreta, E. Rojí, M. Larrauri, and I. Álvarez, "Sustainability assessment methodology for industrial buildings: three case studies," Civil Engineering and Environmental Systems, vol. 33, no. 2, pp. 106-124, 2016.

[45] G. Heravi, M. Fathi, and S. Faeghi, "Multi-criteria group decision-making method for optimal selection of sustainable industrial building options focused on petrochemical projects," Journal of Cleaner Production, vol. 142, pp. 2999-3013, 2017.

[46] A. Formisano and F. M. Mazzolani, "On the selection by MCDM methods of the optimal system for seismic retrofitting and vertical addition of existing buildings," Computers and Structures, vol. 159, pp. 1-13, 2015.

[47] G. Terracciano, G. Di Lorenzo, A. Formisano, and R. Landolfo, "Cold-formed thin-walled steel structures as vertical addition and energetic retrofitting systems of existing masonry buildings," European Journal of Environmental and Civil Engineering, vol. 19, no. 7, 2015.

[48] E. K. Zavadskas and J. Antucheviciene, "Multiple criteria evaluation of rural building's regeneration alternatives," Building and Environment, vol. 42, no. 1, pp. 436-451, 2007.

[49] E. K. Zavadskas and J. Antucheviciene, "Evaluation of buildings' redevelopment alternatives with an emphasis on the multipartite sustainability," Journal of Strategic Property Management, vol. 8, no. 2, pp. 121-128, 2010.

[50] S. Hosseini, A. De la Fuente, and O. Pons, "Multicriteria decision-making method for sustainable site location of post-disaster temporary housing in urban areas," Journal of Construction Engineering and Management, vol. 142, no. 9, 2016.

[51] H. Malekly, S. Meysam Mousavi, and H. Hashemi, "A fuzzy integrated methodology for evaluating conceptual bridge design," Expert Systems with Applications, vol. 37, no. 7, pp. 4910-4920, 2010.

[52] A. Farkas, "Multi-criteria comparison of bridge design," Acta Polytechnica Hungarica, vol. 8, no. 1, pp. 173-191, 2011.

[53] H. Gervásio and L. Simões da Silva, "A probabilistic decisionmaking approach for the sustainable assessment of infrastructures," Expert Systems with Applications, vol. 39, no. 8, pp. 7121-7131, 2012.

[54] V. Balali, A. Mottaghi, O. Shoghli, and M. Golabchi, "Selection of appropriate material, construction technique, and structural system of bridges by use of multicriteria decisionmaking method," Transportation Research Record: Journal of the Transportation Research Board, vol. 2431, no. 1, pp. 7987, 2014.

[55] P. Jakiel and D. Fabianowski, "FAHP model used for assessment of highway RC bridge structural and technological arrangements," Expert Systems with Applications, vol. 42, no. 8, pp. 4054-4061, 2015.

[56] V. Yepes, T. García-Segura, and J. M. Moreno-Jiménez, “A cognitive approach for the multi-objective optimization of 
RC structural problems," Archives of Civil and Mechanical Engineering, vol. 15, no. 4, pp. 1024-1036, 2015.

[57] M. Kripka, V. Yepes, and C. J. Milani, "Selection of sustainable short-span bridge design in Brazil," Sustainability, vol. 11, no. 5, p. 1307, 2019.

[58] Y.-M. Wang, J. Liu, and T. M. S. Elhag, "An integrated AHPDEA methodology for bridge risk assessment," Computers and Industrial Engineering, vol. 54, no. 3, pp. 513-525, 2008.

[59] S. Dabous and S. Alkass, "Decision support method for multi-criteria selection of bridge rehabilitation strategy," Construction Management and Economics, vol. 26, pp. 883893, 2008.

[60] M. Rashidi, B. Samali, and P. Sharafi, "A new model for bridge management: Part B: decision support system for remediation planning," Australian Journal of Civil Engineering, vol. 14, no. 1, pp. 46-53, 2016.

[61] M. Mikawi, "A methodology for the evaluation of the use of advanced composites in structural civil engineering applications," Composites Part B: Engineering, vol. 27, pp. 203215, 1996.

[62] M. Rashidi, M. Ghodrat, B. Samali, B. Kendall, and C. Zhang, "Remedial modelling of steel bridges through application of Analytical Hierarchy Process (AHP)," Applied Sciences, vol. 7, no. 2, p. 168, 2017.

[63] T.-Y. Chen, "The extended linear assignment method for multiple criteria decision analysis based on interval-valued intuitionistic fuzzy sets," Applied Mathematical Modelling, vol. 38, no. 7-8, pp. 2101-2117, 2014.

[64] F. Begic and N. H. Afgan, "Sustainability assessment tool for the decision making in selection of energy system-Bosnian case," Energy, vol. 32, no. 10, pp. 1979-1985, 2007.

[65] M. Jovanovic, N. Afgan, P. Radovanovic, and V. Stevanovic, "Sustainable development of the Belgrade energy system," Energy, vol. 34, no. 5, pp. 532-539, 2009.

[66] T. Kaya and C. Kahraman, "Multicriteria renewable energy planning using an integrated fuzzy VIKOR \& AHP methodology: the case of Istanbul," Energy, vol. 35, no. 6, pp. 2517-2527, 2010.

[67] J. Barros, M. Coira, M. López, and A. Gochi, “Assessing the global sustainability of different electricity generation systems," Energy, vol. 89, pp. 473-489, 2015.

[68] S. J. W. Klein and S. Whalley, "Comparing the sustainability of U.S. electricity options through multi-criteria decision analysis," Energy Policy, vol. 79, pp. 127-149, 2015.

[69] M. Montajabiha, "An extended PROMETHE II multicriteria group decision making technique based on intuitionistic fuzzy logic for sustainable energy planning," Group Decision and Negotiation, vol. 25, no. 2, pp. 221-244, 2016.

[70] S. Väisänen, M. Mikkilä, J. Havukainen, L. Sokka, M. Luoranen, and M. Horttanainen, "Using a multi-method approach for decision-making about a sustainable local distributed energy system: a case study from Finland," Journal of Cleaner Production, vol. 137, pp. 1330-1338, 2016.

[71] A. Fetanat and E. Khorasaninejad, "A novel hybrid MCDM approach for offshore wind farm site selection: a case study of Iran," Ocean and Coastal Management, vol. 109, pp. 17-28, 2015.

[72] S. Medina-González, A. Espuña, and L. Puigjaner, "An efficient uncertainty representation for the design of sustainable energy generation systems," Chemical Engineering Research and Design, vol. 131, pp. 144-159, 2018.

[73] S. Gumus, M. Kucukvar, and O. Tatari, "Intuitionistic fuzzy multi-criteria decision making framework based on life cycle environmental, economic and social impacts: the case of U.S. wind energy," Sustainable Production and Consumption, vol. 8, pp. 78-92, 2016.

[74] A. De la Fuente, J. Armengou, O. Pons, and A. Aguado, "Multi-criteria decision-making model for assessing the sustainability index of wind-turbine support systems: application to a new precast concrete alternative," Journal of Civil Engineering and Management, vol. 23, no. 2, 2017.

[75] O. Pons, A. De la Fuente, J. Armengou, and A. Aguado, "Towards the sustainability in the design of wind towers," Energy Procedia, vol. 115, pp. 41-49, 2017.

[76] A. Gento, "Selection of a dam in the river basin of river Duero by promethee method," in Proceedings of the International Conference on Modelling and Simulation, pp. 341-347, Orlando, FL, USA, May 2004.

[77] A. Afshar, M. A. Mariño, M. Saadatpour, and A. Afshar, "Fuzzy TOPSIS multi-criteria decision analysis applied to Karun reservoirs system," Water Resources Management, vol. 25, no. 2, pp. 545-563, 2011.

[78] X. Sun, P. Ning, X. Tang et al., "Environmental risk assessment system for phosphogypsum tailing dams," The Scientific World Journal, vol. 2013, Article ID 680798, 13 pages, 2013.

[79] C. Martin, Y. Ruperd, and M. Legret, "Urban stormwater drainage management: the development of a multicriteria decision aid approach for best management practices," European Journal of Operational Research, vol. 181, no. 1, pp. 338-349, 2007.

[80] X. Dong, S. Zeng, J. Chen, and D. Zhao, “An integrated assessment method of urban drainage system: a case study in Shenzhen City, China," Frontiers of Environmental Science and Engineering in China, vol. 2, no. 2, pp. 150-156, 2008.

[81] Y. Tahmasebi and F. Yazdandoost, "An integrated framework to evaluate resilient-sustainable urban drainage management plans using a combined-adaptive MCDM technique," Water Resources Management, vol. 32, no. 8, pp. 2817-2835, 2018.

[82] A. De la Fuente, O. Pons, A. Josa, and A. Aguado, "Multicriteria decision making in the sustainability assessment of sewerage pipe systems," Journal of Cleaner Production, vol. 112, pp. 4762-4770, 2016.

[83] J. Jaber and M. Mohsen, "Evaluation of non-conventional water resources supply in Jordan," Desalination, vol. 136, no. 1-3, pp. 83-92, 2001.

[84] A. Abrishamchi, A. Ebrahimian, M. Tajrishi, and M. A. Mariño, "Case study: application of multicriteria decision making to urban water supply," Journal of Water Resources Planning and Management, vol. 131, no. 4, pp. 326-335, 2005.

[85] U. Pascal, Q. Xie, and L. Xu, "A fuzzy TOPSIS model framework for ranking sustainable water supply alternatives," Water Resources Management, vol. 31, pp. 2579-2593, 2017.

[86] G. Chhipi-Shrestha, K. Hewage, and R. Sadiq, "Selecting sustainability indicators for small to medium sized urban water systems using fuzzy-ELECTRE," Water Environment Research, vol. 89, no. 3, pp. 238-249, 2017.

[87] M. Kucukvar, S. Gumus, G. Egilmez, and O. Tatari, "Ranking the sustainability performance of pavements: an intuitionistic fuzzy decision making method," Automation in Construction, vol. 40, pp. 33-43, 2014.

[88] D. Jato-Espino, J. Rodriguez-Hernandez, V. C. AndrésValeri, and F. Ballester-Muñoz, "A fuzzy stochastic multi- 
criteria model for the selection of urban pervious pavements," Expert Systems with Applications, vol. 41, no. 15, pp. 6807-6817, 2014.

[89] C. Torres-Machí, A. Chamorro, E. Pellicer, V. Yepes, and C. Videla, "Sustainable pavement management," Transportation Research Record: Journal of the Transportation Research Board, vol. 2523, no. 1, pp. 56-63, 2015.

[90] J. Santos, S. Bressi, V. Cerezo, and D. Lo Presti, "SUP\&R DSS: SUP\&R DSS: a sustainability-based decision support system for road pavements," Journal of Cleaner Production, vol. 206, pp. 524-540, 2019.

[91] S. Hashemkhani, N. Rezaeiniya, E. Zavadskas, and Z. Turskis, "Forest roads locating based on AHP and on COPRAS-G methods: an empirical study based on Iran," Economics and Management, vol. 4, pp. 6-20, 2011.

[92] U. Oses, E. Rojí, J. Cuadrado, and M. Larrauri, "Multiplecriteriadecision-making tool for local governments to evaluate the global and local sustainability of transportation systems in urban areas: case study," Journal of Urban Planning and Development, vol. 144, no. 1, 2017.

[93] A. De la Fuente, A. Blanco, S. Cavalaro, and A. Aguado, "Sustainability assessment of precast concrete segments for TBM tunnels," in Proceedings of the 2nd International Conference on Concrete Sustainability, Madrid, Spain, June 2016.

[94] A. De la Fuente, A. Blanco, J. Armengou, and A. Aguado, "Sustainability based-approach to determine the concrete type and reinforcement configuration of TBM tunnels linings. Case study: extension line to Barcelona Airport T1," Tunnelling and Underground Space Technology, vol. 61, pp. 179-188, 2017.

[95] N. Asgari, A. Hassani, D. Jones, and H. H. Nguye, "Sustainability ranking of the UK major ports: methodology and case study," Transportation Research Part E: Logistics and Transportation Review, vol. 78, pp. 19-39, 2015.

[96] G. Banias, C. Achillas, C. Vlachokostas, N. Moussiopoulos, and S. Tarsenis, "Assessing multiple criteria for the optimal location of a construction and demolition waste management facility," Building and Environment, vol. 45, no. 10, pp. 2317-2326, 2010.

[97] M. Rochikashvili and J. C. Bongaerts, "Multicriteriadecision-making for sustainable wall paints and coatings using Analytic Hierarchy Process," Energy Procedia, vol. 96, pp. 923-933, 2016.

[98] O. Ugwu and T. Haupt, "Key performance indicators and assessment methods for infrastructure sustainability-a South African construction industry perspective," Building and Environment, vol. 42, no. 2, pp. 665-680, 2007.

[99] J. Saparauskas, "The main aspects of sustainability evaluation in construction," in Proceedings of the 9th International Conference on Modern Building Materials, Structures and Techniques, Vilnius, Lithuania, May 2007.

[100] J. P. Reyes, J. T. San-José, J. Cuadrado, and R. Sancibrian, "Health \& Safety criteria for determining the sustainable value of construction projects," Safety Science, vol. 62, pp. 221-232, 2014.

[101] N. Dobrovolskiiene and R. Tamosiuniene, "An index to measure sustainability of a business project in construction industry: Lithuanian case," Sustainability, vol. 8, no. 1, 2016.

[102] ISO, Environmental Management:-Life Cycle AssessmentPrinciples and Framework, International Standards Organization, Geneva, Switzerland, 2006.
[103] ISO, Environmental Management-Life Cycle Assessment-Requirements and Guidelines, International Standards Organization, Geneva, Switzerland, 2006.

[104] D. Hunkeler, K. Lichtenvort, G. Rebitzer et al., Environmental Life Cycle Costing, SETAC Publications, Brussels, Belgium, 2008.

[105] UNEP/SETAC, "Guidelines for social life cycle assessment of products," in Proceedings of the Paris SETAC Life Cycle Initiative United Nations Environment Programme, Paris, France, January 2009.

[106] M. Marzourk and S. Azab, "Environmental and economic impact assessment of construction and demolition waste disposal using system dynamics," Resources, Conservation and Recycling, vol. 82, pp. 41-49, 2014.

[107] UNEP/SETAC, The Methodological Sheets for Subcategories in Social Life Cycle Assessment (S-LCA), UNEP-SETACLifeCycle Initiative, Paris, France, 2013.

[108] I. J. Navarro, V. Yepes, and J. V. Martí, "Social life cycle assessment of concrete bridge decks exposed to aggressive environments," Environmental Impact Assessment Review, vol. 72, pp. 50-63, 2018

[109] P. Vincke and J. Brans, "A preference ranking organization method. The PROMETHEE method for MCDM," Management Science, vol. 31, pp. 647-656, 1985.

[110] Y. B. Shin, S. Lee, S. G. Chun, and D. Chung, "A critical review of popular multi-criteria decision making methodologies," Issues in Information Systems, vol. 14, no. 1, pp. 358-365, 2013.

[111] M. Velasquez and P. T. Hester, "An analysis of multi-criteria decision making methods," International Journal of Operations Research, vol. 10, no. 2, pp. 56-66, 2013.

[112] V. Penadés-Plà, T. García-Segura, J. V. Martí, and V. Yepes, "A review of multi-criteria decision-making methods applied to the sustainable bridge design," Sustainability, vol. 8, no. 12, p. 1295, 2016.

[113] E. Roszkowska, "Multi-criteria decision making models by applying the TOPSIS method to crisp and interval data," Multiple Criteria Decision Making, vol. 6, 2011.

[114] C. C. Hung and L. H. Chen, "A fuzzy TOPSIS decision making model with Entropy weight under intuitionistic fuzzy environment," in Proceedings of the International Multi-Conference of Engineers and Computer Scientists IMECS, Hong Kong, Japan, March 2009.

[115] P. Goodwin and G. Wright, Decision Analysis for Management Judgment, John Wiley \& Sons, Chichester, UK, 2000.

[116] A. Pires, N. B. Chang, and G. Martinho, "An AHP-based fuzzy interval TOPSIS assessment for sustainable expansion of the solid waste management system in Setúbal Peninsula, Portugal," Resources, Conservation and Recycling, vol. 56, pp. 7-21, 2011.

[117] G. Kabir, R. Sadiq, and S. Tesfamariam, "A review of multi-criteria decision-making methods for infrastructure management," Structure and Infrastructure Engineering, vol. 10, no. 9, pp. 1176-1210, 2014.

[118] M. E. Ahmine, J. Pailles, and N. Perry, "Comparison of different multiple-criteria decision analysis methods in the context of conceptual design: application to the development of a solar collector structure," in Proceedings of Joint Conference on Mechanical, Design Engineering \& Advanced Manufacturing, Toulouse, France, June 2014.

[119] V. Podvezko, "The comparative analysis of MCDA methods SAW and COPRAS," Engineering Economics, vol. 22, no. 2, 2011. 
[120] İ. Kaya, M. Colak, and F. Terzi, "Use of MCDM techniques for energy policy and decision-making problems: a review," International Journal of Energy Research, vol. 42, no. 7, pp. 2344-2372, 2018.

[121] A. Mardani, A. Jusoh, K. Nor, Z. Khalifah, N. Zakwan, and A. Valipour, "Multiple criteria decision-making techniques and their applications-a review of the literature from 2000 to 2014," Economic Research, vol. 28, 2015.

[122] F. Sitorus, J. J. Cilliers, and P. R. Brito-Parada, "Multi-criteria decision making for the choice problem in mining and mineral processing: applications and trends," Expert Systems with Applications, vol. 121, pp. 393-417, 2019.

[123] K. Renganath and M. Suresh, "Supplier selection using fuzzy MCDM techniques: a literature review," in Proceedings of the IEEE International Conference on Computational Intelligence and Computing Research (ICCIC), Chennai, India, December 2016.

[124] M. A. Ilgin, S. M. Gupta, and O. Battaïa, "Use of MCDM techniques in environmentally conscious manufacturing and product recovery: state of the art," Journal of Manufacturing Systems, vol. 37, pp. 746-758, 2015.

[125] S. A. Khan, A. Chaabane, and F. T. Dweiri, "Multicriteriadecision-making methods application in supply chain management: a systematic literature review," in MultiCriteria Methods and Techniques Applied to Supply Chain Management, IntechOpen, London, UK, 2018.

[126] M. Noryani, S. M. Sapuan, M. T. Mastura et al., "Multicriteriadecision-making tools for material selection of natural fibre composites: a review," Journal of Mechanical Engineering and Sciences, vol. 12, no. 1, pp. 3330-3353, 2018.

[127] L. Scholten, N. Schuwirth, P. Reichert, and J. Lienert, "Tackling uncertainty in multi-criteria decision analysis-an application to water supply infrastructure planning," European Journal of Operational Research, vol. 242, no. 1, pp. 243-260, 2015.

[128] N. Radwan, M. Senousy, and A. Riad, "Neutrosophic AHP Multi-Criteria Decision Making method applied on the selection of learning management system," International Journal of Advancements in Computing Technology, vol. 8, no. 5, pp. 95-105, 2016.

[129] L. A. Zadeh, "Fuzzy sets," Information and Control, vol. 8, no. 3, pp. 338-353, 1965.

[130] K. Atanassov, "Intuitionistic fuzzy sets," Fuzzy Sets and Systems, vol. 20, no. 1, pp. 87-96, 1986.

[131] F. Smarandache, A Unifying Field in Logics, Neutrosophy: Neutrosophic Probability, Set and Logic, American Research Press, Rehoboth, NM, USA, 1999. 


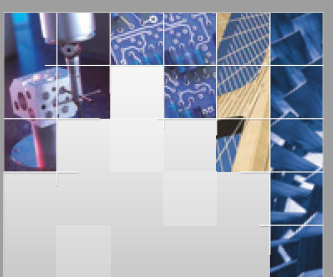

\section{Enfincering}
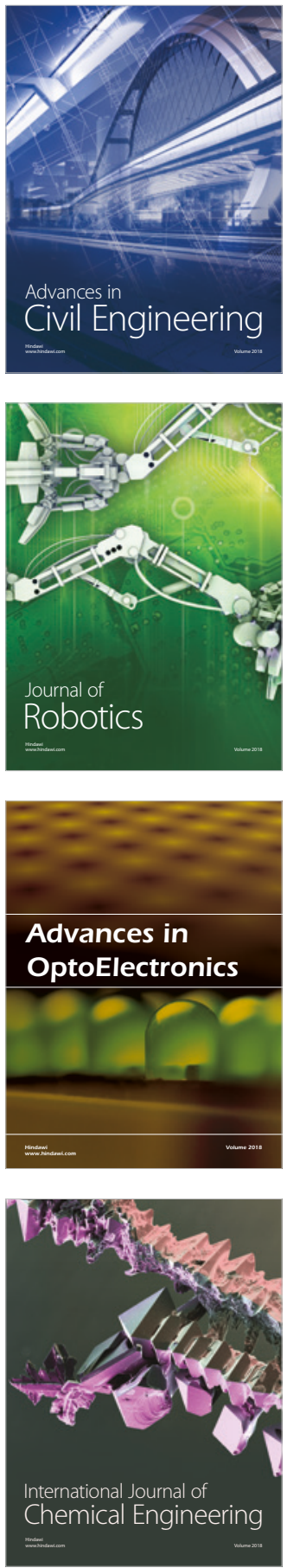

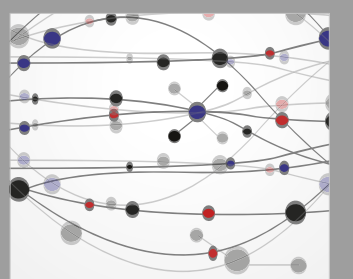

\section{Rotating \\ Machinery}

The Scientific World Journal

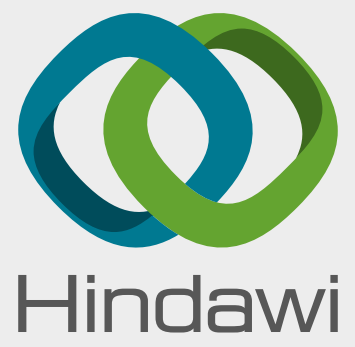

Submit your manuscripts at

www.hindawi.com
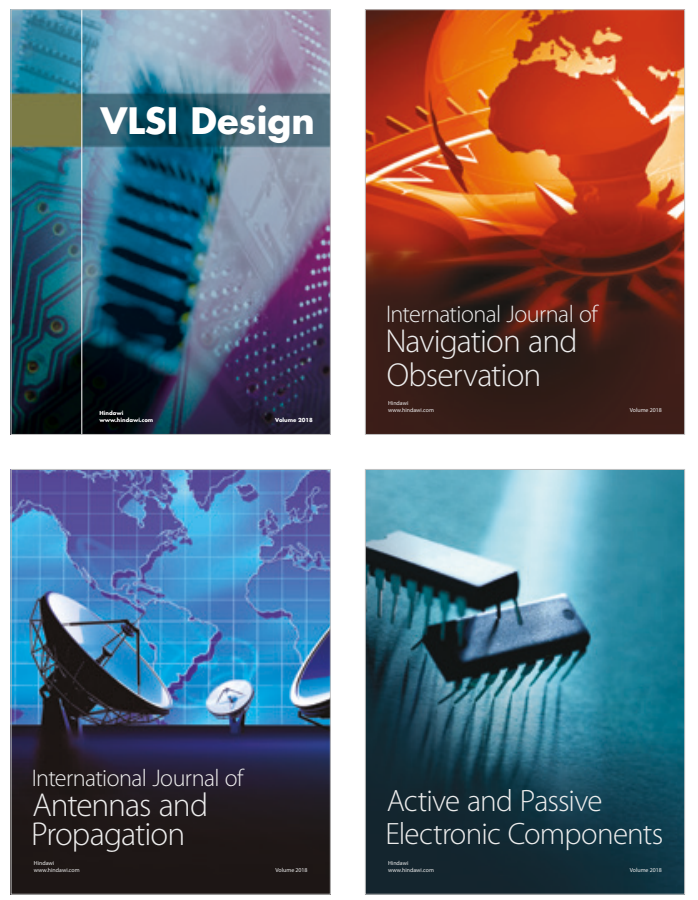
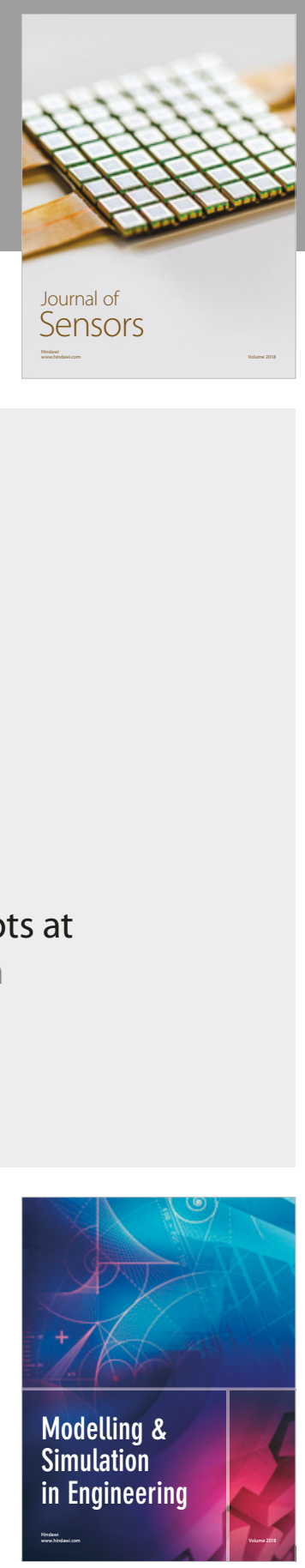

\section{Advances \\ Multimedia}
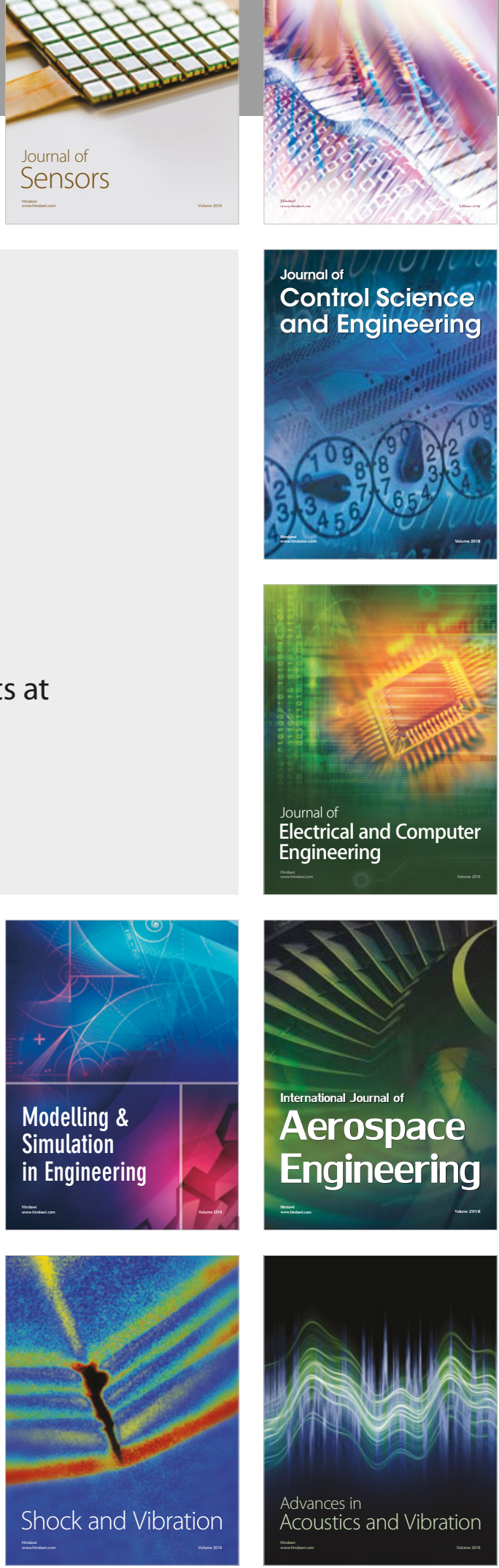